\title{
Science Education at High School: a VISIR Remote Lab Implementation
}

\author{
Ignacio Evangelista ${ }^{1}$, Juan A. Farina ${ }^{1}$, María I. Pozzo ${ }^{2}$, Elsa Dobboletta ${ }^{2}$, Gustavo R. Alves ${ }^{3}$ \\ Javier García-Zubía ${ }^{4}$, Unai Hernández ${ }^{4}$, Susana T. Marchisio ${ }^{5}$, Sonia B. Concari ${ }^{5}$, Ingvar Gustavsson ${ }^{6}$ \\ ${ }^{1}$ Polytechnic Institute of Rosario, National University of Rosario, Argentina \\ ${ }^{2}$ National Scientific and Technical Research Council, Argentina \\ ${ }^{3}$ Polytechnic Institute of Porto, Portugal \\ ${ }^{4}$ University of Deusto, Spain \\ ${ }^{5}$ Faculty of Exact Sciences, Engineering and Surveying, National University of Rosario, Argentina \\ ${ }^{6}$ Blekinge Institute of Technology, Sweden
}

\begin{abstract}
Experimentation is crucial in science teaching at any education level. Students' motivation and collaborative work are also essential in order to achieve positive learning outcomes. This article portrays the implementation of remote experimentation using VISIR in a Physics subject at high-school level. Qualitative and quantitative data were analyzed for this particular case study in order to shed light on the influence of VISIR on students' motivation. Results showed that VISIR remote lab is a powerful tool to arouse interest in electronic circuit topics.
\end{abstract}

Keywords-VISIR remote lab; Physics; motivation; teamwork; collaborative work; inductive teaching.

\section{INTRODUCTION}

A remote laboratory is a type of lab characterized by being the user and the device physically apart and hence interacting via some communication means, mostly the Internet. They are developed in order to reproduce the same performance as a real experiment [1]. Remote labs are considered one of the major shifts in a century of engineering education [2]. All such systems share some advantages that can be summarized in: accessibility, availability and safety [3]. In addition, remote labs are likely to appeal to young students given their condition of digital natives [4].

VISIR (Virtual Instruments and Systems in Reality) is an open remote lab dedicated to experimenting with electrical and electronic circuits [5]. The project was launched in 2006 by the Blekinge Institute of Technology (BTH) in Sweden together with National Instruments in the USA and Axiom EduTECH in Sweden. It was financially supported by the BTH and the Swedish Governmental Agency for Innovation Systems [6].

By the end of 2015, the project VISIR+ was launched, cofounded by the Erasmus+ Programme from the European Union. This project aims at spreading and developing the use of remote labs in Latin America, contributing to scaffold STEM courses in those regions. The initiative has been developed in partnership within institutions from Europe: the Blekinge Institute of Technology (BTH), the School of Engineering of Polytechnic of Porto (ISEP), the University of Deusto (UDeusto), the Spanish University for Distance Education (UNED) and the Carinthia University of Applied Sciences (CUAS); and from Latin America: the Federal Institute of Education, Science and Technology of Santa Catarina (IFSC), the Federal University of Santa Catarina (UFSC), the Pontifical Catholic University of Rio de Janeiro (PUCRio), the National University of Santiago del Estero (UNSE) and the National University of Rosario (UNR).

The Polytechnic Institute of Rosario (IPS) is a secondary school which belongs to the National University of Rosario (UNR) and is consequently related to the VISIR+ Project. It has roughly 1,300 students in secondary level, 600 having technical undergraduate education and a staff of 400 people. This paper describes the implementation of VISIR remote laboratory at the Polytechnic Institute of Rosario in high-school level in an annual physics course.

Physics IV is a common-core compulsory subject for students in 4th year of high school. During 3rd year, students choose from six areas to further a specialization for the following three years: Constructions, Computer Science, Electronics, Industrial Processes, Chemistry and Mechanics. This experience was conducted with the group of students pursuing a technical degree in Constructions. There were 37 students (aged between 16 and 17), all of them freshmen, i.e. taking the course for the first time.

Amongst topics of thermodynamics and electricity and magnetism, the physics course described in this work comprises a module on Circuits which is usually developed along four weeks in the second semester (4 hours per week in 3 sessions). Even though students have studied some very basic circuits issues in previous years, this is the first opportunity where the topic is addressed comprehensively. 
A hands-on laboratory session with 37 students where they handle electrical equipment requires at least two assistant teachers in addition to the teacher in charge to supervise students' work. Normally students attend only one physic laboratory session by the end of the module. However, the advantages of VISIR enabled the teacher to set up experimental activities more often since it is available 24/7. A remote lab serves several purposes, namely:

- Providing an opportunity for students to develop experimental competences;

- Presenting the students with the chance to apply the concepts which they learn in the classroom in a laboratory context.

- Motivating students by means of 'doing' rather than, for instance, solving calculations exercises.

- Facing difficulties that normally arise during a laboratory session so as to be prepared for the handson laboratory.

- Enhancing group interaction and cooperation

Here VISIR was particularly intended to be both a support and an introduction to the target theory concepts, following an inductive approach. As a context for learning, students were presented with an experimental situation and had to collect some data; the fundamental concepts were then either proposed by the teacher or discovered by the students in order to account for the scenario analyzed [7]. Besides, remote experimentation with VISIR was meant to strengthen students' motivation in order to improve their learning [4] and to encourage teamwork and discussions on results.

It is important to mention that due to time constraints, the hands-on laboratory could not be performed in this opportunity and thus VISIR was the only laboratory experience students had during this module.

Thanks to the VISIR+ Project, the deployment of a physical equipment for VISIR is scheduled for the immediate future. However, since it has not been installed yet, the VISIR equipment was provided by the University of Deusto.

This paper aims at analyzing the didactic experience using VISIR in the given context of IPS from two perspectives: highschool students' motivation and class cooperative team-work The research methodology can be described as a case study; data gathered is combined with descriptive views to make an analysis of the experience focusing on the two aspects mentioned above [8], [9]. This paper is organized in 4 sections, Section II presents an overview of the activities done and how they were performed throughout the course, Section III describes the data collection methods carried out during this research, Section IV presents the main results of the analysis and Section $\mathrm{V}$ addresses the conclusion of this experience and the perspectives for the future.

\section{IMPLEMENTATION}

The Circuits Module in Physics IV at IPS follows a module on Electrostatics so it begins with an introduction to some electrodynamics concepts. After describing the principles that govern the electronic circuits, the idea of 'remote laboratory'

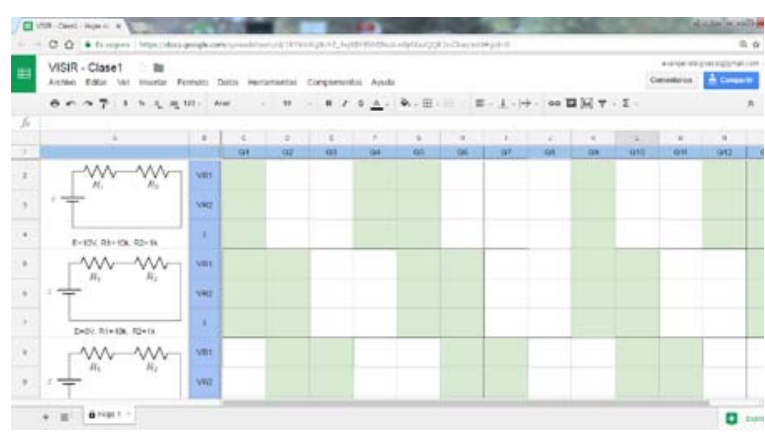

Fig. 1 Google Spreadsheet used during the first session.

was presented. This description focused on comparing a remote laboratory with a hands-on laboratory and with a simulation. In order to achieve that, these three tools for working with circuits were described and showed by the instructor. VISIR was presented afterwards including an explanation of how it worked, which is a crucial phase [2].

According to the contents of the unit, DC Experiments supported by VISIR were performed; only resistors and the variable DC power supply were used.

Four activities using VISIR were performed during November 2016, two in the second week, one during the third and the last one during the fourth. Each session lasted approximately 60 minutes after a short explanation of the objectives of each task. Since there were only 13 computers in the laboratory used for this experience, students worked in trios with the exception of two people who worked on their own, each one on a different computer; they were all asked to keep their groups for the rest of the virtual lab sessions. Attendance to the sessions was not compulsory and no homework was assigned. Their work with VISIR had no direct impact on their final score, albeit the work performed by each person was assessed by the instructor and accounted for their continuous evaluation mark; moreover, sessions were intended to help them underpin the unit contents.

The first session was aimed at helping students get familiar with VISIR, build some basic series circuits and measure currents and voltages; the whole work was supervised by the instructor and an assistant teacher. The activity was presented as a competition-like task where students had to complete a spreadsheet shared on Google Drive (Fig. 1) with their

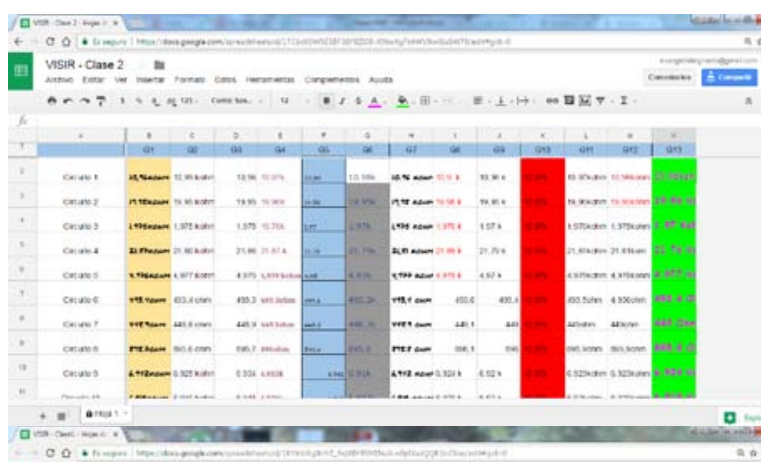

Fig. 2 Google Spreadsheet used for the second session, after being filled by the students. 


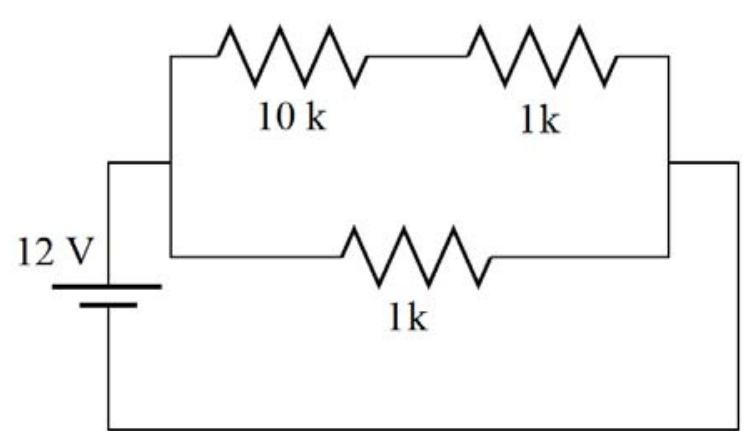

Fig. 3 One of the circuits used in session no. 3.

measurements on different circuits, this allowed them to compare their results with the rest of the class during the activity. Once a group finished their task, cooperation was encouraged by means of asking the faster students to help those who were experiencing difficulties rather than having the teacher to cater for them. 10 out of the 13 groups managed to measure what they were asked with few or no mistakes by the end of the class.

The second session was similar to the first one in terms of competition setup. This time the instructor and two assistant teachers were in charge of the class. In this case, students were asked to interconnect resistors, measure the equivalent resistance and write the data in a spreadsheet shared with their colleagues (shown in Fig. 2). Then, a value of equivalent resistance was proposed and students had to find an arrange of resistors that had the desired equivalent value. Every group dealt with the activity successfully.

After these sessions, experiment results were discussed in the following lesson and some key physic concepts were inferred from those results thus encouraging active learning [7]. Some calculation exercises were done to complement the theory review and the lab activities. Discussions about the differences between the results in the lab and those from calculations were stimulated.

The objective of the third session was to carry out experiments to help students infer Kirchhoff's Laws. This session involved circuits with interconnected resistors and voltage and current measurements (an example is shown in Fig. 3 ). The only instructor in charge of this session assessed orally some groups' understanding of the underlying phenomena and ability to explain the results obtained.

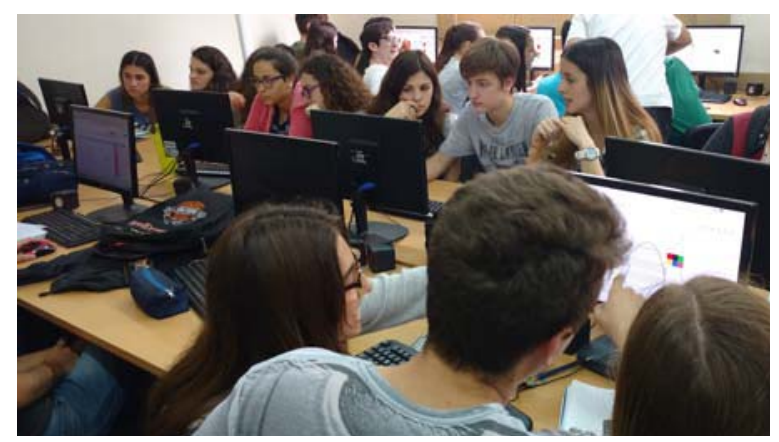

Fig. 4 Students working during the fourth VISIR session
The last session was different in that the activity was presented during one class and students were expected to work with their groups the following day without major assistance from the teacher in a full collaborative team-based environment. This working session with VISIR was the last class of the year, even after the exam on Circuits and had the purpose of evaluating students' experimental operational abilities with the virtual laboratory.

The role of the instructor/teacher and assistants was to provide instructional scaffolding throughout the laboratory sessions and encourage the use of VISIR outside the classroom. Tasks were planned so as to present an increasing cognitive challenge and foster autonomous work so that the learners could get insight of electronics experimental work and become capable of solving tasks on their own by the end of the year. Assistant teachers were still required for the remote lab sessions but in these occasions their focus shifted towards providing instructional support rather than merely supervising the appropriate manipulation of electronic devices as being the case of hands-on laboratories. In other words, teaching requirements have been adapted to pursuing the learning aims [10].

Students' experimental competences were expected to be developed while acquiring the means to analyze and describe the physics principles of circuits in a learning context which awakened their interest to learn the target topic.

\section{DATA COLLECTION}

Data collection focuses on the effectiveness of VISIR in strengthening students' motivation and in encouraging teamwork. Three main aspects were taken into consideration to tackle this issue: students' access to the virtual laboratory, their impressions on VISIR and teacher's opinion on the implementation, recorded in a Teacher's Satisfaction Questionnaire.

Information from students' experience was elicited from VISIR's log-register, as well as from a Students' Satisfaction Questionnaire which used a Likert-scale 1-less to 4-most and addressed two open questions; 35 out of the 37 students answered the questionnaire. The Teachers' Satisfaction Questionnaire consisted in an open question so that the teacher could state his impressions on the didactical implementation.

The emphasis of this work is laid on analyzing to what extent VISIR can enhance students' motivation and promote teamwork.

\section{RESULTS}

The log-register provided information on the individual access to VISIR remote lab, but as most class work was carried out in groups and since students from one group did not always use the same log account during working sessions, it was not possible to track individual student's access. What can be observed is that every group overall online time was at least 210 minutes, the approximate duration of the in-class working sessions. There are only 3 out of the 13 groups whose overall online time was higher than 210 minutes, which implies that at least one of their members worked on their own outside the class, even though it is not possible to identify the user. This 
TABLE I

Results of The Student' SATisfaction Questionnaire

\begin{tabular}{|c|c|c|c|c|c|}
\hline & & $\begin{array}{l}\text { I disagree } \\
\text { (1) }\end{array}$ & $\begin{array}{l}\text { I partially agree } \\
\text { (2) }\end{array}$ & $\begin{array}{l}\text { I agree } \\
\text { (3) }\end{array}$ & $\begin{array}{l}\text { I fully agree } \\
\text { (4) }\end{array}$ \\
\hline Q1 & I liked the activities using VISIR & $0.0 \%$ & $5.7 \%$ & $60.0 \%$ & $34.3 \%$ \\
\hline Q2 & $\begin{array}{l}\text { I would recommend using VISIR } \\
\text { usually to teach DC Circuits in } \\
\text { this subject }\end{array}$ & $0.0 \%$ & $2.9 \%$ & $48.6 \%$ & $48.6 \%$ \\
\hline Q3 & $\begin{array}{l}\text { I wish I had remote labs in other } \\
\text { subjects }\end{array}$ & $5.7 \%$ & $25.7 \%$ & $28.6 \%$ & $40.0 \%$ \\
\hline Q4 & $\begin{array}{l}\text { I have always shared experiment } \\
\text { results with my peers }\end{array}$ & $2.9 \%$ & $25.7 \%$ & $40.0 \%$ & $31.4 \%$ \\
\hline Q5 & $\begin{array}{l}\text { I have usually had problems with } \\
\text { the server }\end{array}$ & $82.9 \%$ & $14.3 \%$ & $0.0 \%$ & $2.9 \%$ \\
\hline
\end{tabular}

rather low number of lab access might be explained taking into account that the use of VISIR did not have a direct quantitative impact on students' final grades nor were there any extra tasks assigned.

Table 1 shows the results of the Student' Satisfaction Questionnaire. When asked if they had liked their experience with the remote laboratory, $84.3 \%$ of the students agreed, stating 3 and 4 and not a single student disagreed. There was also a widespread agreement with the fact that they would recommend using VISIR on a regular basis to teach DC circuits, $97.2 \%$ of the students fully agreeing or agreeing. Answers to question Q3 also back up this idea: 68.6\% agreed or fully agreed with the fact that they would enjoy having remote labs in other subjects.

An aspect that may have contributed to students' interests was the description of how VISIR worked; in fact 12 students mentioned that feature when they answered the open question about what they considered to be the most interesting aspect of using VISIR. This supports that undergraduate and postgraduate students [10] as well as high-school students pursuing a technical degree do value getting to know modern technologies and their possibilities [11].

In spite of being a fundamental subject, the DC Circuits module may not be considered essential for these students given the fact that it is not closely related to their degree context. Notwithstanding, they were asked to pick freely at least one of the modules of the curriculum that they considered the most interesting, and 10 out of the 35 answered 'Circuits'. It is possible to believe that this interest was stimulated by the activities performed using the virtual laboratory, this idea is conveyed by the fact that those 10 students answered 3 and 4 to the previous questions.

Enhanced teamwork can be proved by the $73 \%$ of students who totally agreed (4) or agreed (3) with the fact that they 'have always shared the results with their peers'. These figures support the general impression of the teacher, recorded in the Teacher's Satisfaction Questionnaire: "students got engaged with the activity, being the majority of them enthusiastic about it. The didactical approach encouraged teamwork and the exchanging of ideas throughout the sessions." Promoting cooperation did also impact positively on the class dynamic. The competence-like set-up of some of the activities had a positive effect on students' interest and participation, as a number of them stated during informal interviews. They seemed to enjoy the fact that they could see what their peers were doing and the results they were getting in the shared Google Drive document (sessions 1 and 2).

Also, a key aspect to the positive results formerly explained may be that there were not any problems with the server or the Internet connection, as $82.9 \%$ of the students pointed out (Q5). Had this happened, results could have undermined VISIR's credibility and reflected students' frustration [3].

\section{CONCLUSIONS}

VISIR proved a useful tool to spur interest on learning DC circuits at high-school level. Motivation was enhanced easily by the fact that a remote laboratory was a new experience for students. High-school students highly value the inclusion of ICTs in lessons and they greatly enjoy experiences that stand out from what they normally do in class. Google Drive is an increasingly widespread tool among students; using it in a learning environment together with the remote lab turned out to be highly motivating and enriching.

In order to achieve positive learning outcomes, it is essential to plan the didactical implementation of a remote lab carefully, taking into account students' natural interest to be challenged and to work in groups. In addition, all the experiments that students are expected to carry out should be thoroughly tested before lab sessions to avoid a counterproductive experience that would end up undermining students' enthusiasm.

This implementation was an innovative experience in the Polytechnic Institute of Rosario. The intention is to extend the usage of VISIR to another group of students during 2017. The objective would also be to collect more data so as to carry out a more detailed analysis using a statistical approach on the effectiveness of experimentation using VISIR on students' learning experience. 


\section{ACKNOWLEDGMENTS}

The authors would like to acknowledge the support of the VISIR Community as well as the financial support provided by the European Commission through grant 561735-EPP-1-20151-PT-EPPKA2-CBHE-JP.

The authors would like to acknowledge all students who contributed to this work.

\section{REFERENCES}

[1] A. V. Fidalgo et al., "Using remote labs to serve different teacher's needs A case study with VISIR and RemotElectLab," 2012 9th International Conference on Remote Engineering and Virtual Instrumentation (REV), pp. 1-6. Bilbao, Spain, 2012.

[2] J. Froyd, P. Wankat and K. Smith, "Five major shifts in 100 years of engineering education,” Proc. IEEE, vol. 100, no. Special Centennial Issue, pp. 1344-1360, May 2012.

[3] M. A. Marques, M. C. Viegas, M. C. Costa-Lobo, A. V. Fidalgo, G. R. Alves, "How Remote Labs Impact on Course Outcomes: Various Practices Using VISIR". IEEE Transactions on Education, vol. 57, no. 3, issue 3, pp. 151-159, August 2014.
[4] M. A. Bochinicchio and A. Longo, "Hands-on Remote Labs:Collaborative Web Laboratories as a Case Study for IT Engineering Classes," IEEE Transactions on Learning Technologies, vol. 2, no. 4, pp. 320-330,October-December 2009.

[5] E. Martin, "Active learning in telecommunication engineering: A case study," Proc. IEEE EDUCON, pp. 1555-1562, Madrid, Spain, Apr. 2010.

[6] M. Tawfik et al., "VISIR: Experiences and Challenges," International Journal of Online Engineering, vol. 8, no. 1, pp. 25-32. February, 2012.

[7] M. J. Prince and R. M. Felder, "Inductive Teaching and Learning Methods: Definitions, Comparisons, and Research Bases," Journal of Engineering Education, vol. 95, issue 2, pp. 123-138, April 2006.

[8] L. Cohen, L. Manion and K. Morrison, "Research Methods in Education," 6th edition. London, Routledge, 2007.

[9] L. Shulman, "Disciplines of Inquiry in Education: an Overview," Educational Researcher, vol. 10, no. 6, pp. 5-23, June-July 1981.

[10] S. B. Concari and S. T. Marchisio, "The Remote Laboratory as a Teaching Resource in the Scientific and Technological Training," Creative Education, vol. 4, no. 10, pp. 33-39, October 2013.

[11] C. Culzoni, "Enseñanza de la Fisica mediada por tecnologías. Diseño con laboratorios remotos". Revista Argentina de Enseñanza de la Ingeniería, Año 1, no. 1. March 2012 (originally in Spanish) 